\title{
Clinical and molecular analysis of patients with defects in $\mu$ heavy chain gene
}

\author{
Eduardo Lopez Granados, ${ }^{1,2}$ Andrea S. Porpiglia, ${ }^{1}$ Mary Beth Hogan, ${ }^{3}$ Nuria Matamoros, ${ }^{4}$ \\ Silvia Krasovec, ${ }^{5}$ Claudio Pignata, ${ }^{6}$ C.I.E. Smith, ${ }^{7}$ Lennart Hammarstrom, ${ }^{8}$ \\ Janne Bjorkander, ${ }^{9}$ Bernd H. Belohradsky, ${ }^{10}$ G. Fontan Casariego, ${ }^{2}$ \\ M.C. Garcia Rodriguez, ${ }^{2}$ and Mary Ellen Conley ${ }^{1,11}$
}

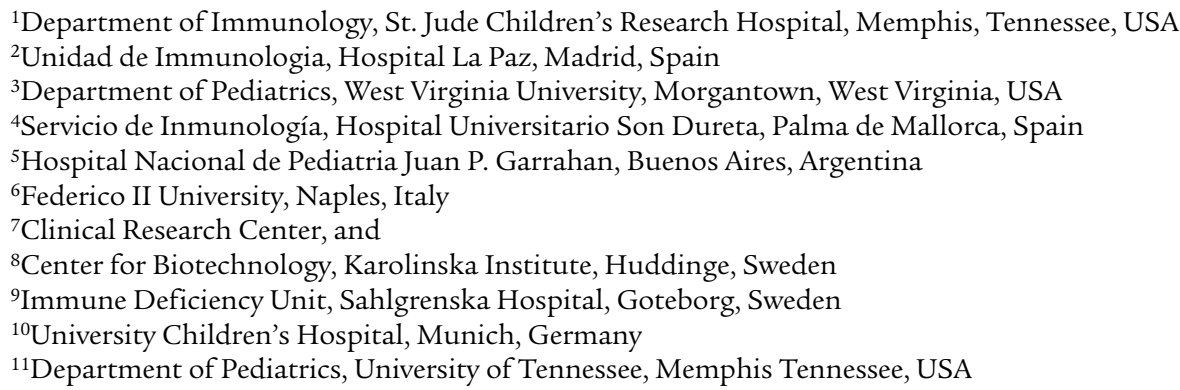

Autosomal recessive disorders of $B$ cell development are rare and heterogeneous. To determine the proportion of affected patients who have defects in the $\mu$ heavy chain (IGHM) gene, we used singlestranded conformational polymorphism analysis to screen genomic DNA from 40 unrelated patients with early onset infections, profound hypogammaglobulinemia, and absent $B$ cells. All of the patients were genotypically normal in $B T K$, the gene that underlies X-linked agammaglobulinemia. Eight different mutations in the $\mu$ heavy chain were identified in 19 members of 12 unrelated families. Four of the mutations were large deletions that removed more than $40 \mathrm{~kb}$ of DNA in the IGHM locus. In six of the 12 families, the affected patients had an identical single base pair substitution, $a \mathrm{G} \rightarrow \mathrm{A}$, at the -1 position of the alternative splice site. Immunoglobulin haplotype analysis showed that this mutation occurred on at least three different haplotypes, indicating that this is a hot spot for mutations. Compared with patients with mutations in Btk, patients with defects in the $\mu$ heavy chain had an earlier onset of disease and more complications. Our study indicates that at least $20-30 \%$ of patients with autosomal recessive defects in B cell development have mutations in the $\mu$ heavy chain.

J. Clin. Invest. 110:1029-1035 (2002). doi:10.1172/JCI200215658.

\section{Introduction}

Studies from our laboratory and from others have shown that defects in the human $\mu$ heavy chain gene can cause profound hypogammaglobulinemia and failure in $\mathrm{B}$ cell development $(1,2)$. However, the relative incidence of this disorder, the spectrum of mutations that can be identified, and the clinical findings in affected patients have not been well defined.

The immunoglobulin heavy chain gene is encoded in a highly complex, polymorphic locus at the telomeric end of chromosome 14q32.2. The locus consists of four separate families of gene segments, $\mathrm{VH}, \mathrm{DH}, \mathrm{JH}$, and $\mathrm{CH}$

Received for publication April 11, 2002, and accepted in revised form July 16, 2002.

Address correspondence to: Mary Ellen Conley, Department of Immunology, St. Jude Children's Research Hospital, 332 North Lauderdale, Memphis, Tennessee 38101, USA. Phone: (901) 495-2576; Fax: (901) 495-3977;

E-mail: maryellen.conley@stjude.org.

Conflict of interest: No conflict of interest has been declared. Nonstandard abbreviations used: single-strand conformational polymorphism (SSCP); cerebrospinal fluid (CSF); X-linked agammaglobulinemia (XLA). genes. Each of these gene families has multiple members that presumably arose by gene duplication, followed by extensive diversification. Immediately adjacent to the telomere of the long arm of chromosome 14 there is a $1,000-\mathrm{kb}$ stretch of DNA containing $80-123 \mathrm{VH}$ segments, depending on the haplotype. Each $\mathrm{VH}$ region has its own promoter and leader sequence (3-6). However, approximately half of the $\mathrm{VH}$ genes are pseudogenes that have defective promoters, heptamer-nonamer recognition sequences, or frameshift mutations (6). The $\mathrm{VH}$ region is followed by a $75-\mathrm{kb}$ fragment of DNA containing a series of 25-30 DH genes (7). These $\mathrm{DH}$ genes can be divided into five tandem repeats of a gene cassette containing six DH genes $(8,9)$. Downstream of the DH region is a $20-\mathrm{kb}$ fragment that encodes six JH gene segments and a powerful lineagespecific enhancer. The last family of gene segments consists of the constant region genes, which in the human are separated into three clusters. The first cluster includes the genes for $\mu$ and $\delta$; the second, which is 80 $\mathrm{kb}$ downstream of the $\mu$ heavy chain, includes $\gamma 3, \gamma 1, \psi \varepsilon$, and $\alpha 1$; and the third, which is $250 \mathrm{~kb}$ downstream of the $\mu$ chain, includes $\gamma 2, \gamma 4, \varepsilon$, and $\alpha 2(10-12)$. 
It has been recognized for many years that the immunoglobulin locus is polymorphic. Some of the antisera that were developed to IgG and IgA subclasses were specific for polymorphic variants within the coding regions for $\gamma 1, \gamma 2, \gamma 3, \gamma 4$, and $\alpha 2(13-15)$. Later studies using Southern blot analysis showed that a DNA probe from the $\mu$ heavy chain switch region crosshybridizes to switch regions from $\varepsilon$ and the $\alpha$ subclasses and reveals multiple polymorphic variants (16). Deletions or duplications within both the $\mathrm{VH}$ region and the constant region clusters of genes are relatively common, occurring in $20-40 \%$ of individuals $(3,5$, 17-21). There is also evidence for extensive allelic variation in the $\mathrm{JH}$ regions of the immunoglobulin locus (22). However, polymorphisms within the $\mu$ heavy chain gene have not been well described.

The $\mu$ heavy chain constant region gene, which is spread over $5 \mathrm{~kb}$, consists of six exons; the first four exons encode the secreted form of the $\mu$ heavy chain. Within the $3^{\prime}$ end of the fourth exon there is an alternative splice site sequence that can be used to join the last two exons of the gene to allow the production of the membrane form of the $\mu$ heavy chain (23). We have previously identified three families with $\mu$ heavy chain deficiency (1). One family had a point mutation at the alternative splice site, another had a large deletion that included the $\mathrm{DH}$ and the $\mathrm{JH}$ genes and the $\mu$ heavy chain constant region gene, and a third had an amino acid substitution on one allele and a large deletion on the other allele. Meffre et al. have described two patients with $\mu$ heavy chain deficiency (2). One had a homozygous frameshift mutation in the first exon of the $\mu$ heavy chain, and the other had a deletion that included the JH genes, the $\mu$ and $\delta$ segment, and the cluster of genes encoding $\gamma 3, \gamma 1, \psi \varepsilon$, and $\alpha 1$. In the current study, we determined the approximate frequency of defects in the $\mu$ heavy chain, and we have identified a mutational hot spot.

\section{Methods}

Patients. Blood or DNA samples from the patients included in this study were referred to our laboratory for analysis of the genetic causes of defects in B cell development. The referring physician was asked to complete a clinical survey at the time the blood or DNA was obtained for molecular studies. The members of F1, F2, F3 (1), and F5 (patient RJ in ref. 24) have been described previously. The referring physician was contacted to obtain follow-up information about the clinical course in patients with proven mutations in the $\mu$ heavy chain.

Mutation analysis. Single-strand conformation polymorphism (SSCP) analysis was performed as described previously using the primer pairs shown in Table $1(1,25)$. Primers permitting the analysis of the region $3^{\prime}$ of $\mu$ heavy chain are also included in Table 1. Unless otherwise noted, all of the reactions were performed under the following PCR conditions: $95^{\circ} \mathrm{C}$ for 5 minutes followed by 30 cycles of $95^{\circ} \mathrm{C}$ for 30 seconds, $56^{\circ} \mathrm{C}$ for 30 seconds, $72^{\circ} \mathrm{C}$ for 30 seconds with a final extension at $72^{\circ} \mathrm{C}$ for 5 minutes. Four of the reactions were digested with restriction enzymes to achieve a fragment length appropriate for SSCP analysis (26). Fragments demonstrating abnormal migration were amplified by PCR, cloned, and sequenced. Each mutation was confirmed using a second independent PCR reaction. The probes used in Southern blot analysis have been described previously (1).

The sequence was compared with the reported sequence for human $\mu$ and $\delta$ constant region, accession number X57331. Because the variable region of an immunoglobulin varies in length, the codon assignment was based on designating the first codon of the $\mathrm{CH} 1$ domain of the $\mu$ heavy chain as the first codon. This differs from our previous publication (1).

\section{Results}

DNA samples from 40 patients with early onset hypogammaglobulinemia and absent $B$ cells and from

Table 1

Primers used to analyze $\mu$ heavy chain locus

\begin{tabular}{|c|c|c|c|c|}
\hline Exon & Sense & Antisense & Enzyme & Size (bp) \\
\hline $1 \mathrm{a}^{\mathrm{A}}$ & 5'-ACTCAGAACGCCACTCAG-3' & 5'-TGAGGTGGCTGCGTACTT-3' & EcoRI & $162+129$ \\
\hline $1 b^{B}$ & 5'-СТТСССАТСАGTССТGAG-3' & 5'-ACGAAGACGCTCACTTTG-3' & HaellI & $157+118$ \\
\hline $2 \mathrm{a}$ & 5'-ACTGCAGTGATTGCTGAG-3' & 5'-AGTGTGCTGGTCACCTTG-3' & & 238 \\
\hline $2 b^{c}$ & 5'-GCTGAGGCCAAAGAGTCT-3' & 5'-AGTGGACCCCTGTGTGTC-3' & & 204 \\
\hline $3 a$ & 5'-CAGAGGCAGTTGCTACTC-3' & 5'-TCACAGCTTCGCCATTCT-3' & & 241 \\
\hline $3 b$ & 5'-ATGACAGCGTGACCATCT-3' & 5'-TCTCCCCGGAATTCCAGT-3' & & 144 \\
\hline $3 c$ & 5'-CAATGCCACTITCAGCGC-3' & 5'-AGGGGTGCTITCCACCATG-3' & & 215 \\
\hline $4 a$ & 5'-CATGGTGGAAAGCACCCCT-3' & 5'-TGGCAGCAAGTAGACATC-3' & & 156 \\
\hline $4 b$ & 5'-СТСАССАССАТСТСТGTТ-3' & 5'-GGTCACATACTTCTCCGG-3' & & 192 \\
\hline $4 c$ & 5'-TCTTCGTGCAGTGGATGC-3' & 5'-GGTTTACCGGTGGACTTG-3' & & 225 \\
\hline $4 d$ & 5'-CAACAGGGTCACCGAGAGG-3' & 5'-GCACTCAGGACCAGTATC-3' & & 242 \\
\hline 5 & 5'-СTGCACTTGСТСТССССА-3' & 5'-CTGTTGGGATCATTTCAC-3' & Rsal & $210+152$ \\
\hline $6^{A}$ & 5'-CGTCACCTTGTTCAAG-3' & 5'-CAGGGCAACAAGCGTATAC-3' & Mbol & $230+194$ \\
\hline \multicolumn{5}{|c|}{$3^{\prime}$ of $\mu$ heavy chain } \\
\hline $40 \mathrm{~kb}$ & 5'-GGGGCAGAAACATCTGTTTCC-3' & 5'-CCCAATTCCGTITTGAGG-3' & & 370 \\
\hline $60 \mathrm{~kb}$ & 5'-CACСTATGTGAGCCACTGGA-3' & 5'-CATGGGATTGCCTTCTTGG-3' & & 560 \\
\hline
\end{tabular}

${ }^{A} A$ nnealing temperature was $60^{\circ} \mathrm{C}$. ${ }^{B} 40$ cycles were used for this reaction. ${ }^{C}$ Annealing temperature was $59^{\circ} \mathrm{C}$. 
Table 2

Mutations in $\mu$ heavy chain

\begin{tabular}{|c|c|c|c|c|c|}
\hline Family number & Nationality & Exon & Codon & Change & Effect \\
\hline $\mathrm{F} 1$ & USA & 4 & 433 & $\mathrm{G} \rightarrow \mathrm{A}$ & splice defect \\
\hline $\mathrm{F} 2$ & Turkish & 75-kb deletion & & & \\
\hline \multirow[t]{2}{*}{ F3 } & USA/Korean & 4 & 412 & $\mathrm{~T} \rightarrow \mathrm{G}$ & Cys $\rightarrow$ Gly \\
\hline & second allele & 300-kb deletion & & & \\
\hline $\mathrm{F} 4$ & USA & 4 & 433 & $\mathrm{G} \rightarrow \mathrm{A}$ & splice defect \\
\hline F5 & Swedish & 4 & 433 & $\mathrm{G} \rightarrow \mathrm{A}$ & splice defect \\
\hline F6 & Spanish & 2 & 168 & AA del & frameshift \\
\hline F7 & Turkish & 125-kb deletion & & & \\
\hline F8 & Spanish & 4 & 433 & $\mathrm{G} \rightarrow \mathrm{A}$ & splice defect \\
\hline F9 & Spanish & 2 & 168 & AA del & frameshift \\
\hline \multirow[t]{2}{*}{ F10 } & Argentinian & 3 & 258 & $\mathrm{G} \rightarrow \mathrm{A}$ & premature stop \\
\hline & second allele & 40-kb deletion & & & \\
\hline F11 & Italian & 4 & 433 & $\mathrm{G} \rightarrow \mathrm{A}$ & splice defect \\
\hline F12 & Italian & 4 & 433 & $\mathrm{G} \rightarrow \mathrm{A}$ & splice defect \\
\hline
\end{tabular}

a group of normal controls were analyzed by SSCP for alterations in the $\mu$ heavy chain. Patients from nine unrelated, previously unstudied families with immunodeficiency were found to have absent PCR products or altered migration of PCR products not seen in the controls. By SSCP analysis, all of the patients appeared to be homozygous for their alterations although only five of the nine families had a known history of consanguinity. The aberrant exons were cloned and sequenced and compared with the mutations detected previously in our laboratory. Table 2 shows the mutations reported previously from our laboratory (families $1-3$ ) and those found in this study (families 4-12). The pedigrees of the families with known consanguinity or more than one affected child are shown in Figure 1. Six of the 12 families had an identical $G \rightarrow A$ base pair substitution in codon 433 at the -1 position of the alternative splice site required for production of the membrane form of $\mu$ heavy chain (Figure 2 ). In addition, this alteration would change the glycine at this codon to serine in the secreted form of $\mu$ heavy chain and the positively charged lysine to the negatively charged glutamic acid in the membrane form of the molecule.

Two Spanish families were found to have an identical 2-bp deletion, an AA deletion, at codon 168 in exon 2. This mutation would result in a frameshift and a premature stop codon. Two Turkish families living in Germany were homozygous for large deletions within the $\mu$ heavy chain locus; however, the deletions were not identical. In both families, the deletion included a large segment of the $\mathrm{D}$ region genes; however, in one family the deletion ended between the membrane exons of $\mu$ heavy chain and the $\delta$ constant region exons. In the

\section{Figure 1}

The pedigrees of the families with known consanguinity or more than one affected family member are shown. Males and females are indicated with squares and circles respectively. A line is drawn through the symbol for an individual who is no longer living. other family, PCR analysis of the regions 3 ' of $\mu$ heavy chain showed that genomic DNA encoding $\delta$ constant region gene and a region $40 \mathrm{~kb} 3^{\prime}$ of $\mu$ heavy chain were absent, whereas DNA for a region $60 \mathrm{~kb} \mathrm{3}$ of $\mu$ heavy chain and the coding sequence for $\gamma 3$ constant region gene were present, indicating that the deletion ended approximately $50 \mathrm{~kb}$ downstream of $\mu$ and $\delta$.

In two families, the affected patient was a compound heterozygote with a deletion on one allele and a single base pair substitution on the other. A two-year-old girl from Argentina (F10-1) had a $G \rightarrow A$ substitution, resulting in the replacement of the wild-type tryptophan with a premature stop codon at amino acid 258
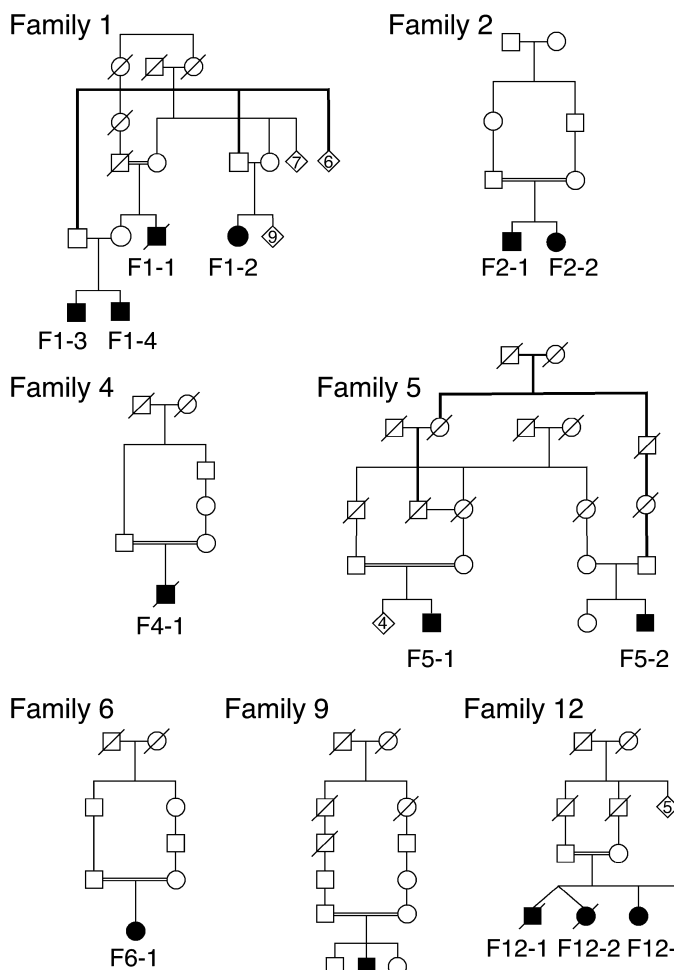

Family 9

Family 12
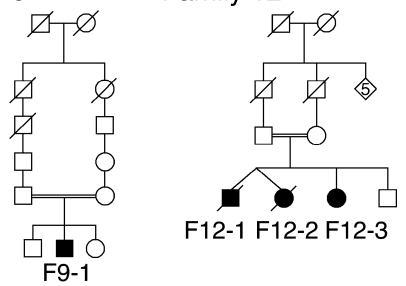


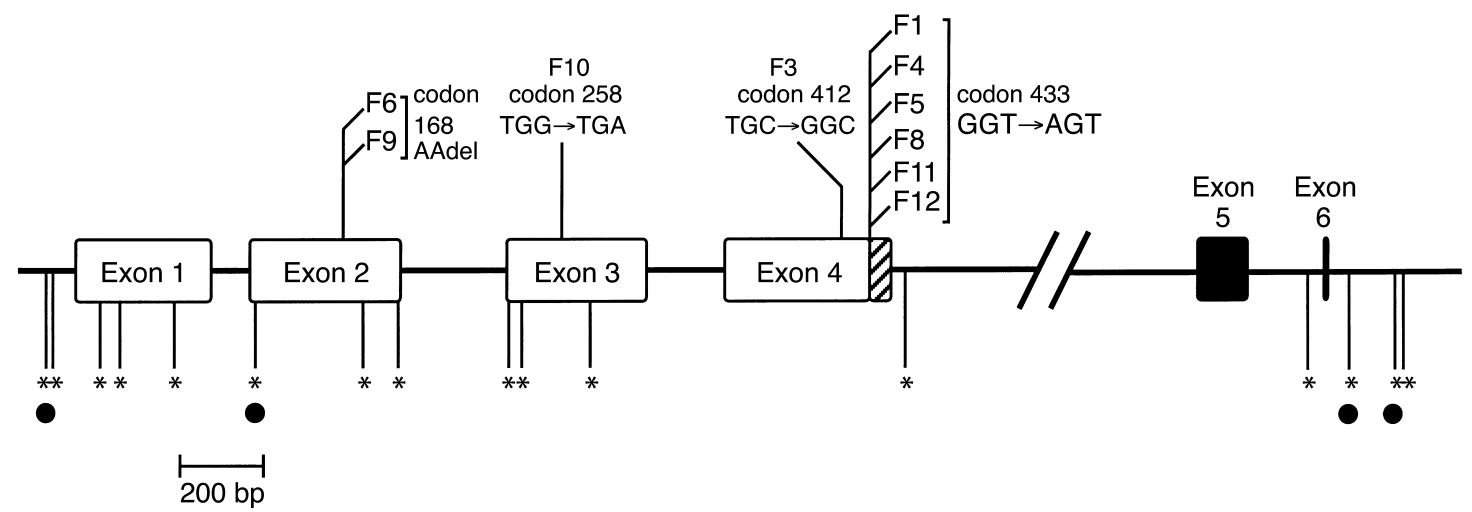

\section{Figure 2}

Schematic diagram of the $\mu$ heavy chain gene. The exons common to the membrane and secretory form of $\mu$ heavy chain are shown in open boxes, the $3^{\prime}$ segment of the secretory form of $\mu$ heavy chain is shown as a hatched pattern, and the two exons that form the membrane exons are shown in filled boxes. The mutations are shown above the gene, and the polymorphic sites are shown below the gene with asterisks. The polymorphic sites that were used to define the haplotypes in patients with shared mutations are marked with a filled circle.

in exon 3 on the paternally derived allele. By SSCP analysis, this alteration was not seen in the maternal DNA sample. However, when the maternal DNA was analyzed by Southern blot, probes for the $\mu$ constant region revealed bands that were $50 \%$ decreased in intensity compared with the bands from control DNA, suggesting a deletion at this site. The bands for VH6 and IgG3 were present at normal intensity in this DNA sample. Previously, we described an American/Korean male with a $T \rightarrow G$ transition at codon 412 in exon 4 of the $\mu$ heavy chain (1). This alteration changes the invariant cysteine required for the intradomain disulfide bond to a glycine. DNA samples from the patient and his father were analyzed by Southern blot with probes for $\mu, \mathrm{VH} 6, \gamma 3$, and the $\varepsilon$ switch region. The bands hybridizing to probes for $\mathrm{VH} 6, \mu$, and $\gamma 3$ showed a $50 \%$ decrease in intensity. The $\varepsilon$ switch probe demonstrated a normal band and a band with altered migration, indicating that the $3^{\prime}$ end of the deletion was between the gene for $\gamma 2$ and the gene for $\varepsilon$.

A variety of polymorphic variants were seen in the controls and the patient population as shown in Table 3 . Most of these alterations occurred outside the coding region or did not result in a change in the amino acid sequence. The reference sequence used as the basis of comparison for this experiment, accession number X57331, had two alterations (a $\mathrm{T}$ insertion at +138 in intron 3 and a $G$ deletion at the +78 position in the $3^{\prime}$ untranslated region) that were not seen in ten patients that we analyzed or in other sequences in the Human Genome Data base (NT_010168.7). Therefore, these alterations are likely to be rare polymorphisms or sequencing errors in the reported sequence.

The amino acid substitutions that were found at codons 76, 190, and 214 were seen in controls as well as patients. Furthermore, the amino acids at these sites are not conserved in murine $\mu$ heavy chain. The aspartic acid $\rightarrow$ asparagine substitution at codon 35 was seen as a heterozygous alteration in a B cell-deficient patient from Germany. However, this amino acid is not conserved in the murine $\mu$ heavy chain sequence, and the patient did not have any other detectable abnormalities in the $\mu$ heavy chain, suggesting that this is a polymorphic variant rather than a mutation. The alteration in codon 219 was seen in a single healthy control; the threonine at this site is conserved in the murine $\mu$ heavy chain. All five of these amino acid substitutions are located in the loops that link the conserved beta strands that form the immunoglobulin domains and therefore would not be expected to have a functional significance. There was some evidence for linkage disequilibrium. For example, both the $\mathrm{C} \rightarrow \mathrm{T}$ substitution at the -52 position in the $5^{\prime}$ intron and the amino acid substitution at codon 190 occurred almost exclusively on the allele demonstrating the $\mathrm{T} \rightarrow \mathrm{C}$ substitution at -66 in the intron $5^{\prime}$ of exon 1.

The occurrence of the mutation at the alternative splice site in patients from several different countries could be

\section{Table 3}

Polymorphic variants in $\mu$ heavy chain

\begin{tabular}{|c|c|c|c|c|}
\hline $\begin{array}{l}\text { Region } \\
\text { of the gene }\end{array}$ & Site & Change & Effect & Frequency \\
\hline $5^{\prime}$ intron & -66 & $\mathrm{~T} \rightarrow \mathrm{C}$ & no change & $118 / 214$ \\
\hline $5^{\prime}$ intron & -52 & $\mathrm{C} \rightarrow \mathrm{T}$ & no change & $3 / 214$ \\
\hline Exon 1 & codon 20 & $\mathrm{ACG} \rightarrow \mathrm{ACA}$ & no change & $1 / 214$ \\
\hline Exon 1 & codon 35 & $\mathrm{GAC} \rightarrow \mathrm{AAC}$ & D35N & $1 / 214$ \\
\hline Exon 1 & codon 76 & $\mathrm{GAC} \rightarrow \mathrm{GAG}$ & D76E & $6 / 262$ \\
\hline Exon 2 & codon 106 & $\mathrm{GCT} \rightarrow \mathrm{GCC}$ & no change & $22 / 56$ \\
\hline Exon 2 & codon 190 & $\mathrm{AGC} \rightarrow \mathrm{GGC}$ & S190G & $15 / 222$ \\
\hline Exon 2 & codon 214 & $\mathrm{GTC} \rightarrow \mathrm{GGC}$ & V214G & $9 / 222$ \\
\hline Exon 3 & codon 219 & $\mathrm{ACA} \rightarrow \mathrm{ATA}$ & T219I & $1 / 266$ \\
\hline Exon 3 & codon 226 & ATC $\rightarrow$ ATT & no change & $3 / 266$ \\
\hline Exon 3 & codon 280 & $\mathrm{ATC} \rightarrow \mathrm{ACC}$ & no change & $3 / 262$ \\
\hline Intron 4 & +30 & $\mathrm{G} \rightarrow \mathrm{A}$ & no change & $1 / 42$ \\
\hline Intron 5 & +138 & $\mathrm{G} \rightarrow \mathrm{A}$ & no change & $16 / 21$ \\
\hline $3^{\prime}$ UT & +50 & $\mathrm{~T} \rightarrow \mathrm{A}$ & no change & $36 / 90$ \\
\hline 3' UT & +155 & $\mathrm{C} \rightarrow \mathrm{G}$ & no change & $6 / 90$ \\
\hline 3' UT & +175 & $A \rightarrow C$ & no change & $2 / 90$ \\
\hline
\end{tabular}


Table 4

Immunoglobulin haplotypes in patients with shared mutations

\begin{tabular}{|c|c|c|c|c|c|c|}
\hline & $\begin{array}{c}5^{\prime} \text { intron } \\
-66\end{array}$ & $\begin{array}{c}\text { exon } 2 \\
\text { codon } 106\end{array}$ & $\begin{array}{l}3^{\prime} \text { UT } \\
+50\end{array}$ & $\begin{array}{l}3^{\prime} \text { UT } \\
+155\end{array}$ & $\begin{array}{l}\text { D14S } \\
1010\end{array}$ & $\begin{array}{r}\text { D14s } \\
118\end{array}$ \\
\hline \multicolumn{7}{|c|}{ Codon $433 \mathrm{G} \rightarrow \mathrm{A}$} \\
\hline F1 & $\mathrm{T} / \mathrm{T}$ & $T / T$ & $\mathrm{~T} / \mathrm{T}$ & $\mathrm{C} / \mathrm{C}$ & $\mathrm{C} / \mathrm{C}$ & $5 / 5$ \\
\hline F4 & $\mathrm{T} / \mathrm{T}$ & $\mathrm{T} / \mathrm{T}$ & $\mathrm{T} / \mathrm{T}$ & $\mathrm{C} / \mathrm{C}$ & $\mathrm{C} / \mathrm{C}$ & $4 / 4$ \\
\hline F5 & $\mathrm{C} / \mathrm{C}$ & $\mathrm{C} / \mathrm{C}$ & $\mathrm{T} / \mathrm{T}$ & $\mathrm{C} / \mathrm{C}$ & $\mathrm{D} / \mathrm{D}$ & $1 / 4$ \\
\hline F8 & $\mathrm{C} / \mathrm{C}$ & $\mathrm{C} / \mathrm{C}$ & $\mathrm{A} / \mathrm{A}$ & $\mathrm{C} / \mathrm{C}$ & $\mathrm{B} / \mathrm{B}$ & $2 / 2$ \\
\hline F11 & $\mathrm{C} / \mathrm{T}$ & $\mathrm{C} / \mathrm{T}$ & $\mathrm{T} / \mathrm{T}$ & $\mathrm{C} / \mathrm{C}$ & $\mathrm{A} / \mathrm{G}$ & $3 / 7$ \\
\hline F12 & $\mathrm{T} / \mathrm{T}$ & $\mathrm{T} / \mathrm{T}$ & $\mathrm{T} / \mathrm{T}$ & $\mathrm{C} / \mathrm{C}$ & $\mathrm{B} / \mathrm{B}$ & $1 / 3$ \\
\hline \multicolumn{7}{|c|}{ Codon 168 AA del } \\
\hline F6 & $\mathrm{C} / \mathrm{C}$ & $T / T$ & $\mathrm{~T} / \mathrm{T}$ & $\mathrm{G} / \mathrm{G}$ & $\mathrm{A} / \mathrm{A}$ & $3 / 3$ \\
\hline F9 & $\mathrm{C} / \mathrm{C}$ & $T / T$ & $\mathrm{~T} / \mathrm{T}$ & $\mathrm{G} / \mathrm{G}$ & $\mathrm{A} / \mathrm{A}$ & $3 / 3$ \\
\hline
\end{tabular}

attributed to shared ancestry or to a recurrent mutation. To examine this question we determined the polymorphic variants of the $\mu$ heavy chain associated with the mutation in each family. In addition, we used two highly polymorphic short tandem repeats located 2.5 and $3 \mathrm{Mb}$ centromeric to $\mu$ heavy chain, D14S1010 and D14S118, to evaluate the extent of the shared haplotype. There was known consanguinity in families 1, 4, 5, 6, 9 and 12; therefore, the affected patients in these families were expected to be homozygous for the polymorphic variants within the gene (Table 4). Of interest, in two families, F5 and F12, the parents of the affected patients were first cousins, yet a crossover between D14S1010 and D14S118 could be shown in both families. A high incidence of recombination at the $3^{\prime}$ end of the immunoglobulin locus has been reported previously (12).
There was no known consanguinity in family 11 , and the affected girl in this family inherited two different immunoglobulin haplotypes bearing the alternative splice defect. Families 1 and 4, who were from the same area of the United States, shared a $2.5-\mathrm{Mb}$ segment of DNA, suggesting that they had an ancestor in common. These two families differed at several sites from the members of F5 and F8. The affected patients in F5 and F8 both had the variant allele at the polymorphic site 66 bp upstream of exon 1, but differed from each other at the variant seen 50-bp downstream of the stop codon in the membrane form of $\mu$ heavy chain. In summary, at least three different immunoglobulin haplotypes bearing the alternative splice defect could be identified, indicating that this is a recurrent mutation. The alternative splice site defect does occur at a CPG dinucleotide, a sequence that is known to be highly vulnerable to mutation. By contrast the two Spanish families with the AA deletion in exon 2 shared identical immunoglobulin polymorphic markers, including the unusual variant $155 \mathrm{bp}$ downstream of the stop codon in the membrane form of the $\mu$ heavy chain, indicating that these patients inherited their defect from a shared ancestor.

A total of 19 patients with defects in the $\mu$ heavy chain were identified (Table 5), eight females and 11 males. Fourteen of the patients are living and are currently 2-53 years old. The mutation in the $\mu$ heavy chain was documented in three of the remaining patients (F2-2, F4-1, and F12-1) and presumed in two patients who died of infections typical of agammaglobulinemia (F1-1 and F12-2). All of the patients had the onset of recurrent infections in the first year of life. The oldest patient, F5-1, was born before Bruton's description of congenital

\section{Table 5}

Clinical findings in patients with $\mu$ heavy chain deficiency

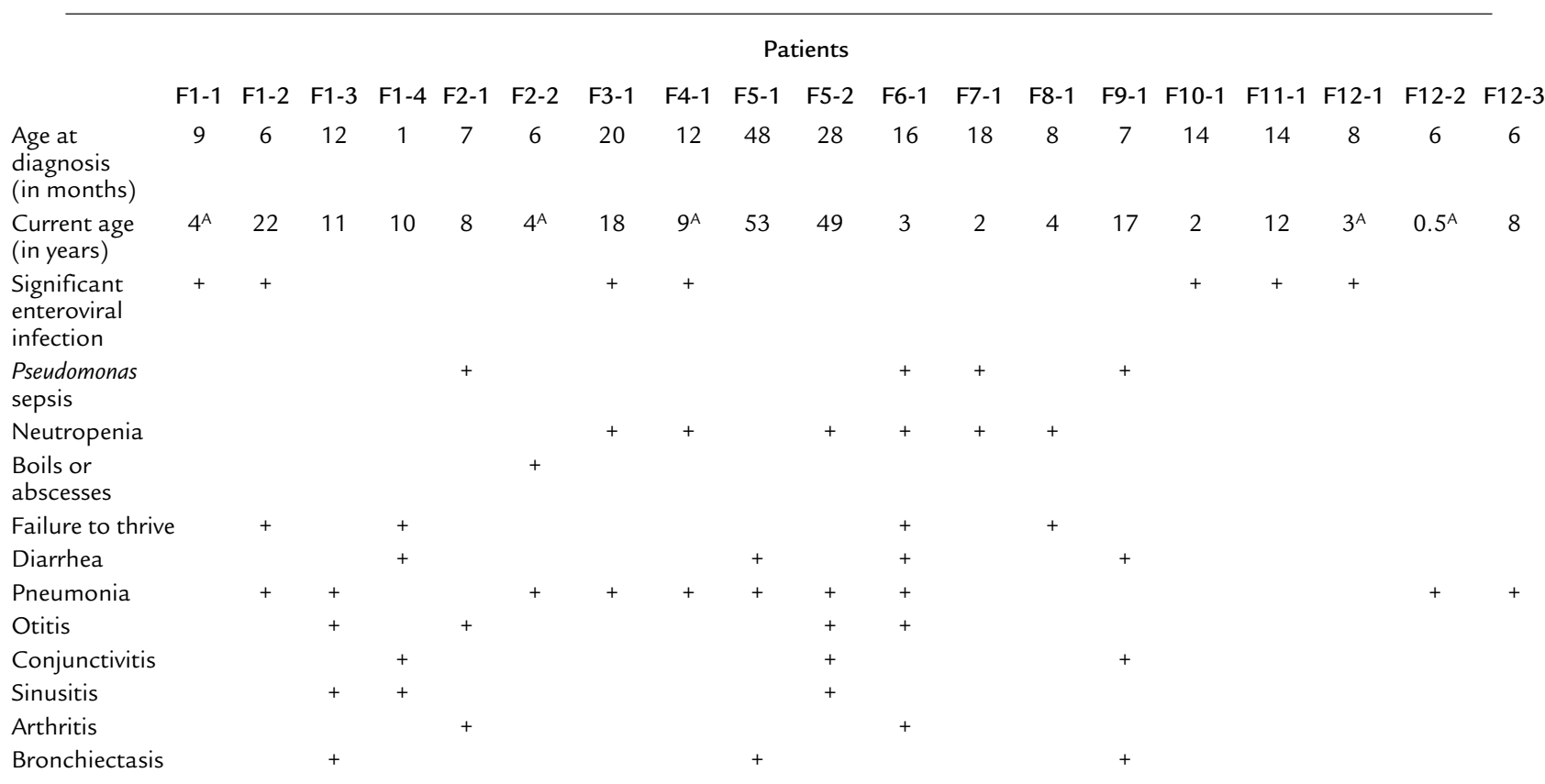

${ }^{\mathrm{A}} \mathrm{Age}$ at death in deceased patients. 
agammaglobulinemia and was recognized to have immunodeficiency at 4 years of age, in 1953 (24). His cousin, F5-2, was born in 1953 and given the diagnosis of agammaglobulinemia at 28 months of age of age in 1955 . One of the patients was evaluated as an infant because of the known family history of immunodeficiency (F1-4). The remaining 16 patients were recognized to have severe hypogammaglobulinemia at a mean of 11 months of age. By contrast, the mean age at diagnosis in patients with a more common cause of agammaglobulinemia, Btk deficiency, is 35 months (27).

The clinical findings in the patients with $\mu$ heavy chain deficiency are typical of those seen in patients with agammaglobulinemia, but tend to be weighted toward the most severe manifestations. (Table 5). The oldest patient, F5-1, was relatively well until about 2 years of age, when he developed recurrent rhinopharyngitis, stomatitis, and gastroenteritis and was treated with multiple courses of antibiotics. He was recognized to have immunodeficiency and was started on gammaglobulin replacement at 4 years of age after his first pneumonia. He developed bronchiectasis during adolescence and was on worker's disability after 30 years of age. He is currently an oxygen-dependent invalid. His cousin, F5-2, had recurrent pharyngitis, otitis, and skin infections as a small child. Since the initiation of gammaglobulin therapy at 2 years of age, he has had recurrent pneumonias and severe blepharoconjunctivitis resulting in some vision loss; however, he has not been hospitalized for infection in the last 25 years.

Seven of the 19 patients had signs and symptoms of significant enteroviral infections. Two patients, F3-1 and F11-1, were recognized to have immunodeficiency when they developed paralysis typical of polio shortly after receiving live polio vaccine. Both patients are currently relatively well but have residual weakness. Loss of developmental milestones attributed to chronic enteroviral encephalitis was seen in F1-1, F1-2, F4-1, F10-1, and F12-1 and was the cause of death in F1-1, F4-1, and F12-1. Echovirus 7 was cultured from the cerebrospinal fluid (CSF) from F1-2 and from F10-1, and an unspecified enterovirus was cultured from the stool of F1-1. CSF cultures and PCR were negative for enterovirus in F4-1 and were not evaluated in F12-1.

Four of the patients were evaluated for immunodeficiency when they developed Pseudomonas sepsis. Infections with this organism were not seen after the patients began gammaglobulin replacement therapy. Neutropenia was also common at the time of diagnosis, but was rarely seen after initiation of therapy. As noted in Table 5, pneumonia, sinusitis, and conjunctivitis were common in the patients with $\mu$ heavy chain deficiency. However, most of the patients were relatively well after gammaglobulin treatment was initiated.

\section{Discussion}

Eight different mutations in the $\mu$ heavy chain were identified in the 12 families included in this study. Four of the mutations were large deletions that removed the
$\mathrm{DH}, \mathrm{JH}$, and enhancer regions as well as the $\mu$ heavy chain constant region gene. A single base pair substitution resulting in a premature stop codon in exon 3 was seen on one allele in one family; a single base pair alteration causing the replacement of an invariant cysteine with glycine in exon 4 was seen on one allele in another family. A 2-bp deletion in exon 2 was seen as a homozygous defect in two unrelated Spanish families who are likely to have a common ancestor based on immunoglobulin haplotype analysis. The last mutation, a single base pair substitution at the -1 position of the alternative splice site in exon 4 , was seen as a homozygous alteration in six of the 12 families in this study. This mutation was seen in patients from several different countries, and it was seen on three different immunoglobulin haplotypes, indicating that this is a recurrent mutation. The alternative splice site mutation destroys an MspI site in the exon 4d PCR product; therefore, a single PCR reaction, followed by MspI digestion, can function as a rapid screening test that identifies over $50 \%$ of the patients with defects in $\mu$ heavy chain because it detects patients with homozygous deletions, as well as patients with the recurrent splice defect.

It is not always easy to distinguish polymorphic variants from mutations. In this study we identified 16 single nucleotide polymorphisms within the $\mu$ heavy chain constant gene. Five of the 16 variants that we observed are associated with amino acid substitutions. One of these amino acid substitutions, the aspartic acid $\rightarrow$ asparagine at codon 35 , was seen a single time as a heterozygous alteration in a patient with a defect in $\mathrm{B}$ cell development. This alteration may be a mutation with deleterious consequences; however, the fact that this amino acid substitution, like the other four amino acid substitutions, occurs in one of the relatively nonconserved loops that link the conserved beta strands of the immunoglobulin domain makes this unlikely. Furthermore, the alterations at codons $35,76,190$, and 214 are at sites that are not conserved in murine $\mu$ heavy chain. Murine and human $\mu$ heavy chain constant region share only $62 \%$ identity in amino acid sequence, consistent with the idea that there is tolerance for a great deal of variability within the loops that link the seven beta strands.

When compared with the more common genetic immunodeficiency, X-linked agammaglobulinemia (XLA), patients with mutations in the $\mu$ heavy chain are more likely to have an earlier onset of disease, and they tend to have more severe complications of their disease. This can be explained, at least in part, by the fact that mutations in Btk, the abnormal gene in XLA, result in a leaky block in $B$ cell development, whereas the $\mu$ heavy chain defect results in a complete block. Almost all patients with XLA do have a small number of $B$ cells and some IgG in the peripheral circulation $(28,29)$. It is likely that the small amount of immunoglobulin that can be found in the serum of patients with XLA provides some clinical benefit. Whether this benefit is due to the antigen-binding regions or the nonspecific $\mathrm{Fc}$ portion 
of the immunoglobulin is not clear. It should be noted that the oldest patient in this series, a 53-year-old man, survived until 4 years of age with frequent courses of antibiotics but without gammaglobulin replacement. He has survived longer than most patients with XLA who were born in the same era. In the last 20 years, the majority of the patients with $\mu$ heavy chain deficiency have been treated with intravenous gammaglobulin and they have not had life-threatening problems after diagnosis when compliance with therapy was good.

Defects in the $\mu$ heavy chain are sufficiently rare to make it difficult to determine the exact frequency of the disorder; however, comparison with a more common genetic immunodeficiency, XLA, is informative. Mutations in the cytoplasmic tyrosine kinase Btk can be identified in $90-95 \%$ of males who have the characteristic findings of XLA: early onset of infections, profound hypogammaglobulinemia, and a marked reduction in the number of peripheral blood B cells (30). In addition, about $10 \%$ of the patients with the characteristic findings of XLA are females (31). Taken together, these findings suggest that approximately $15 \%$ of patients with defects in B cell development have an autosomal recessive or multifactorial cause of their disease. Our analysis of patients with defects in early B cell development but normal Btk, indicate that $20-30 \%$ of these patients (9 of 40 unrelated families) have mutations in the coding regions of the $\mu$ heavy constant region gene. Because the immunoglobulin heavy chain locus is complex, it is possible that additional patients have mutations at this locus that are not detected by our screening assay. Single patients with defects in B cell development and mutations in $\lambda 5$, Ig $\alpha$, or BLNK have been identified (32-34), but in $50-60 \%$ of the remaining affected patients the nature of the underlying defect remains unknown.

\section{Acknowledgments}

We appreciate the willingness of the patients and their families to participate in these research studies. We thank Judy Rush for secretarial assistance. These studies were supported by grants from the NIH (AI-25129), the National Cancer Institute (P30 CA21765), the Assisi Foundation, American Lebanese Syrian Associated Charities, and by funds from the Federal Express Chair of Excellence.

1. Yel, L., et al. 1996. Mutations in the mu heavy chain gene in patients with agammaglobulinemia. N. Engl. J. Med. 335:1486-1493.

2. Meffre, E., et al. 2001. Immunoglobulin heavy chain expression shapes the B cell receptor repertoire in human B cell development. J. Clin. Invest. 108:879-886. doi:10.1172/JCI200113051.

3. Walter, M.A., Surti, U., Hofker, M.H., and Cox, D.W. 1990. The physical organization of the human immunoglobulin heavy chain gene complex. EMBO J. 9:3303-3313.

4. Matsuda, F., et al. 1993. Structure and physical map of 64 variable segments in the $3^{\prime} 0.8$ - megabase region of the human immunoglobulin heavy-chain locus. Nat. Genet. 3:88-94.

5. Cook, G.P., et al. 1994. A map of the human immunoglobulin VH locus completed by analysis of the telomeric region of chromosome 14q. Nat. Genet. 7:162-168.

6. Matsuda, F., et al. 1998. The complete nucleotide sequence of the human immunoglobulin heavy chain variable region locus. J. Exp. Med. 188:2151-2162.
7. Schroeder, H.W.J., et al. 1988. Physical linkage of a human immunoglobulin heavy chain variable region gene segment to diversity and joining region elements. Proc. Natl. Acad. Sci. USA. 85:8196-8200.

8. Ichihara, Y., Matsuoka, H., and Kurosawa, Y. 1988. Organization of human immunoglobulin heavy chain diversity gene loci. EMBO J. 7:4141-4150.

9. Corbett, S.J., Tomlinson, I.M., Sonnhammer, E.L.L., Buck, D., and Winter, G. 1997. Sequence of the human immunoglobulin diversity (D) segment locus: a systematic analysis provides no evidence for the use of DIR segments, inverted D segments, "minor" D segments or D-D recombination. J. Mol. Biol. 270:587-597.

10. Flanagan, J.G., and Rabbitts, T.H. 1982. Arrangement of human immunoglobulin heavy chain constant region genes implies evolutionary duplication of a segment containing gamma, epsilon and alpha genes. Nature. 300:709-713.

11. Bottaro, A., de Marchi, M., Migone, N., and Carbonara, A.O. 1989. Pulsedfield gel analysis of human immunoglobulin heavy-chain constant region gene deletions reveals the extent of unmapped regions within the locus. Genomics. 4:505-508.

12. Hofker, M.H., Walter, M.A., and Cox, D.W. 1989. Complete physical map of the human immunoglobulin heavy chain constant region gene complex. Proc. Natl. Acad. Sci. USA. 86:5567-5571.

13. Terry, W.D., Fahey, J.L., and Steinberg, A.G. 1965. GM and INV factors in subclasses of human IgG. J. Exp. Med. 122:1087-1102.

14. Natvig, J.B., and Kunkel, H.G. 1968. Genetic markers of human immunoglobulins. The Gm and Inv Systems. Ser. Haematol. I:66-96.

15. Kunkel, H.G., Smith, W.K., Joslin, F.G., Natvig, J.B., and Litwin, S.D. 1969. Genetic marker of the $\gamma \mathrm{A} 2$ subgroup of $\gamma \mathrm{A}$ immunoglobulins. Nature. 223: $1247-1248$.

16. Migone, N., et al. 1983. Multiple DNA fragment polymorphisms associated with immunoglobulin mu chain switch-like regions in man. Proc. Natl. Acad. Sci. USA. 80:467-471.

17. Shin, E.K., et al. 1991. Physical map of the $3^{\prime}$ region of the human immunoglobulin heavy chain locus: clustering of autoantibody-related variable segments in one haplotype. EMBOJ. 10:3641-3645.

18. Walter, M.A., and Cox, D.W. 1991. Nonuniform linkage disequilibrium within a $1,500-\mathrm{kb}$ region of the human immunoglobulin heavy-chain complex. Am. J. Hum. Genet. 49:917-931.

19. Olsson, P.G., Rabbani, H., Hammarstrom, L., and Smith, C.I. 1993. Novel human immunoglobulin heavy chain constant region gene deletion haplotypes characterized by pulsed-field electrophoresis. Clin. Exp. Immunol. 94:84-90.

20. Brusco, A., et al. 1995. Variability of the immunoglobulin heavy chain constant region locus: a population study. Hum. Genet. 95:319-326.

21. Brusco, A., et al. 1997 . The G4 gene is duplicated in $44 \%$ of human immunoglobulin heavy chain constant region haplotypes. Hum. Genet. 100:84-89.

22. Mattila, P.S., Schugk, J., Wu, H., and Makela, O. 1995. Extensive allelic sequence variation in the J region of the human immunoglobulin heavy chain gene locus. Eur. J. Immunol. 25:2578-2582.

23. Early, P., et al. 1980. Two mRNAs can be produced from a single immunoglobulin mu gene by alternative RNA processing pathways. Cell. 20:313-319.

24. Kulneff, N., Pedersen, K.O., and Waldenstrom, J. 1955. Drei Falle von Agammaglobulinamie; Ein klinischer, genetischer und physikalischchemischer Beitrag zur Kenntnis des Proteinstoffwechsels. Schweiz. Med. Wschr. 85:363-368.

25. Conley, M.E., Fitch-Hilgenberg, M.E., Cleveland, J.L., Parolini, O., and Rohrer, J. 1994. Screening of genomic DNA to identify mutations in the gene for Bruton's tyrosine kinase. Hum. Mol. Genet. 3:1751-1756.

26. Sheffield, V.C., Beck, J.S., Kwitek, A.E., Sandstrom, D.W., and Stone, E.M. 1993. The sensitivity of single-strand conformation polymorphism analysis for the detection of single base substitutions. Genomics. 16:325-332.

27. Farrar, J.E., Rohrer, J., and Conley, M.E. 1996. Neutropenia in X-linked agammaglobulinemia. Clin. Immunol. Immunopath. 81:271-276.

28. Conley, M.E. 1985. B cells in patients with X-linked agammaglobulinemia. J. Immunol. 134:3070-3074.

29. Nomura, K., et al. 2000. Genetic defect in human X-linked agammaglobulinemia impedes a maturational evolution of pro-B cells into a later stage of pre-B cells in the B-cell differentiation pathway. Blood. 96:610-617.

30. Conley, M.E., Mathias, D., Treadaway, J., Minegishi, Y., and Rohrer, J. 1998. Mutations in Btk in patients with presumed X-linked agammaglobulinemia. Am. J. Hum. Genet. 62:1034-1043.

31. Conley, M.E., and Sweinberg, S.K. 1992. Females with a disorder phenotypically identical to X-linked agammaglobulinemia. J. Clin. Immunol. 12:139-143.

32. Minegishi, Y., et al. 1998. Mutations in the human $\lambda 5 / 14.1$ gene result in B cell deficiency and agammaglobulinemia. J. Exp. Med. 187:71-77.

33. Minegishi, Y., et al. 1999. Mutations in Ig $\alpha$ (CD79a) result in a complete block in B cell development. J. Clin. Invest. 104:1115-1121.

34. Minegishi, Y., et al. 1999. An essential role for BLNK in human B cell development. Science. 286:1954-1957. 